\title{
Toxicity Test with BSLT (Brine Shrimp Lethality Test) Method on Methanol, Ethyl Acetate Extract, Hexane on Seeds and Rind of Matoa extract (Pometia pinnata)
}

\author{
HANAFI ${ }^{1}$, CANDRA IRAWAN ${ }^{2}$, SEPTILINA MELATI SIRAIT ${ }^{1 *}$, \\ LILIS SULISTIAWATY ${ }^{2}$ and SRI REDJEKI SETYAWATI ${ }^{1}$ \\ 1'Department of Food Quality Assurance, Polytechnic AKA Bogor, Indonesia. \\ ${ }^{2}$ Department of Analytical Chemistry, Polytechnic AKA Bogor, Indonesia. \\ ${ }^{*}$ Corresponding author E-mail: septilinamelati.aka@ gmail.com
} http://dx.doi.org/10.13005/ojc/360618

(Received: October 12, 2020; Accepted: December 05, 2020)

ABSTRACT

\begin{abstract}
Matoa seed and rind as an antioxidant for humans need to be strengthened by research on the toxicity. One of the toxicity tests is using the Brine Shrimp Lethality Test (BSLT) method. The mortality value was determined using a probit analysis to determine the toxicity value using the Lethal Concentration $\left(\mathrm{LC}_{50}\right.$ ) on the solvent fractions of ethyl acetate, methanol and hexane. The toxicity value (LC- ${ }_{50}$ ) of Matoa seed extract in hexane, ethyl acetate and methanol solvents were 153, 90 ppm, 141, 09 ppm and 153.65 $\mathrm{ppm}$. The toxicity value (LC- ${ }_{50}$ ) of Matoa rind extract in hexane, ethyl acetate and methanol were 109, 34 ppm, 172, 98 ppm and $139.41 \mathrm{ppm}$, respectively. All the solvents had bioactive compound which had high toxicity because they have $\mathrm{LC}_{50}<1000 \mathrm{ppm}$. The highest toxicity was found in the rind of the matoa fruit extracted using hexane and methanol solvent with $\mathrm{LC}_{50}$ values $109,34 \mathrm{ppm}$ and $139.41 \mathrm{ppm}$, while the hexane extract had the lowest toxicity was $172.98 \mathrm{ppm}$.
\end{abstract}

Keywords: Matoa, Hexane, Ethyl acetate, Methanol, Toxicity, Brine Shrimp Lethality Test.

\section{INTRODUCTION}

Matoa fruit (Pometia pinata) is a typical Indonesian fruit. Matoa fruit is a sweet fruit like rambutan or longan, this fruit is rich in vitamine $E$ and vitamine $C$. vitamine $E$ in matoa fruit can help keep skin moist and its vitamine $C$ content can be used as an antioxidant. Based on previous research, matoa has been widely used as traditional medicine because it has plant chemical compound that are active substances (phytochemical). Secondary metabolites produced by plants include alkaloid, terpene, flavonoid, lignan, steroid, saponin, phenolic, and glucoside ${ }^{1}$.

The active compound produced by the matoa plant had been tested for their efficacy, including as an antidiabetic on the stem bark of the matoa $^{2}$, as an antioxidant and antimicrobial substance in matoa leaves ${ }^{3}$. In addition, the antimicrobial test on the rind of the matoa fruit has been carried out using plate diffusion and fluid diffusion test. Based

This is an Open Access article licensed under a Creative Commons license: Attribution 4.0 International (CC- BY). Published by Oriental Scientific Publishing Company @ 2018

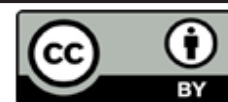


on previous research, it showed that research on the seed and rind of the matoa fruit has not been done much. One of the studies by Irawan in 2017, showed the presence of antioxidant activity in the rind and seed of the matoa fruit as much as $1195 \mu \mathrm{g} / \mathrm{mL}$ and $7656 \mu \mathrm{g} / \mathrm{mL}^{4}$

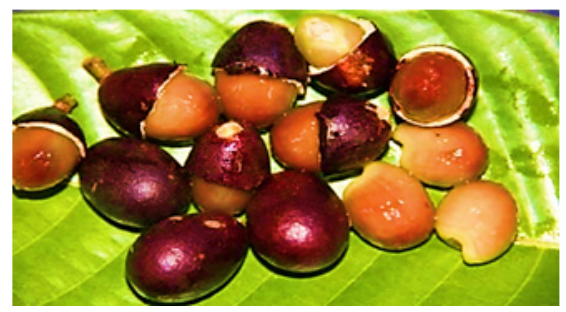

Fig. 1. Seeds and rind of Matoa (Pometia pinata)

The benefit of Matoa seed and skin as antioxidant for humans need to be strengthened by research on the toxicity of the seed and skin of the Matoa fruit. One of the toxicity tests is using the Brine Shrimp Lethality Test (BSLT) method. The mortality value was determined using a probit analysis to determine the toxicity value using the Lethal Concentration ( $\mathrm{LC}_{50}$ ) on the solvent fractions of ethyl acetate, methanol and hexane.

The aim of this experiment was to determine the toxicity of the extract of methanol, ethyl acetate and hexane seed and rind of matoa (Pometia pinata) using the BSLT method. The result obtained were then compared to determine the best solvent in reducing the toxicity of the seedsand rind of the matoa fruit.

\section{MATERIAL AND METHODS}

\section{Materials and Chemicals}

The materials used in this study were matoa seeds (Pometia pinnata), matoa fruit rind, Arthemia salina shrimp larvae, methanol (pa), ethyl acetate, n-hexane, concentrated hydrochloric acid $(\mathrm{HCl})$, ammonia, chloroform, Dragendorf reagent. , Mayer reagent, Mg powder, Amyl alcohol, Diethyl ether, Lieberman reagent, $\mathrm{FeCl}_{3}$, DMSO and sodium chloride. The tools used are: rotary evaporator, UV lamp, aquarium for shrimp larvae, petri dishes, vortex, centrifuge, incubator, erlenmeyer, glass beaker, vial bottle, test tube, dropper pipette and other glass tools.

\section{Extraction of Matoa Fruit Seeds and Skins}

The fruit of the matoa is peeled, then the outer shell and seed are separated. Furthermore, the seed and rind of the matoa fruit were washed, drained and dried in direct sunlight for 4 hours. A total of $50 \mathrm{~g}$ of simplicia seeds and matoa fruit rind were extracted with a solvent ratio of $1: 10(\mathrm{w} / \mathrm{v})$. The solvents used were methanol, ethyl acetate and $n$-hexane. Extraction was carried out for $2 \times 24$ hours by maceration. The maceration results were filtered, then evaporated with a rotary evaporator at a temperature of $50^{\circ} \mathrm{C}$ so that the extract of the seed and rind of the matoa fruit was obtained.

\section{Phytochemical Test of Matoa Fruit Seeds and Rind}

a. Alkaloid Identification

A total of $100 \mathrm{mg}$ of Matoa seeds and rind extract, added $5 \mathrm{~mL}$ of $10 \% \mathrm{HCl}$ and diluted ammonia to $\mathrm{pH} 8$, then extracted with $20 \mathrm{~mL}$ chloroform, then the extract was evaporated. The extract was dissolved with $2 \mathrm{~mL} \mathrm{HCl} 2 \%$ and divided into 3 tubes. The first tube was used as a comparison, the second tube was added by Mayer reagent and the third tube was added by Dragendorff reagent. If there is a white precipitate with a Mayer reagent, an orange-red precipitate with a Dragendorf reagent in the sample ${ }^{5}$.

b. Flavonoid Identification

As much as $100 \mathrm{mg}$ of Matoa seeds and rind extract were dissolved in $100 \mathrm{~mL}$ of hot water, then boiled for $5 \mathrm{~min}$ then filtered. As much as $5 \mathrm{~mL}$ of filtrate was added $0.1 \mathrm{mg}$ of $\mathrm{Mg}$ powder, $1 \mathrm{~mL}$ of concentrated $\mathrm{HCL}$ and $1 \mathrm{~mL}$ of amyl alcohol and then shaken vigorously. The presence of flavonoids was shown by the formation of red, yellow or orange in the amyl alcohol layer ${ }^{5}$.

c. Triterpenoid and Steroid Identification

A total of $100 \mathrm{mg}$ Matoa seeds and rind extract were added with $25 \mathrm{~mL}$ of diethyl ether and then shaken. The diethyl ether layer was separated and 2-3 Lieberman-Burchard reagents were added. Triterpenoids were present when blue solutions were formed and steroid were present when green solutions are formed. ${ }^{5}$

\section{d. Saponin Identification}

A total of $100 \mathrm{mg}$ Matoa seeds and rind extract were added with $10 \mathrm{~mL}$ of hot distilled water, cooled, and shaken vigorously for 10 minutes. Saponins were present when a solid foam was formed and on the addition of 1 drop of $\mathrm{HCl}_{2} \mathrm{~N}$ (the foam remains stable). ${ }^{5}$ 


\section{e. Tanin Identification}

A total of $100 \mathrm{mg}$ Matoa seeds and rind extract were added using $1 \mathrm{~mL}$ ethanol and $1 \mathrm{~mL}$ aquadest. The filtrate obtained was then added a few drops of $\mathrm{FeCl}_{3} 1 \%$. The presence of tannin compounds was indicated by the formation of green, blue or purple. ${ }^{5}$

\section{Toxicity Test of the BSLT Method (Brine Shrimp Lethality Test)}

Artemia salina shrimp eggs were hatched in a dark and light vessel. The dark zone was where the eggs and aerators were located, while the light zone was placed by lights to provide lighting in the hatchery and to separate the cyst. In the vessel filled with $\pm 50-100 \mathrm{mg}$ of shrimp eggs to be hatched, then the vessel was divided into 2 parts dark zone and light zone which were given a light that was turned on for 48 hours.

Ten larvae of Artemia salina shrimp were put into the test solution with concentrations of 1000 , 100, 50 and $10 \mathrm{ppm}$ and were carried out on the blank as a control. Each test solution was repeated 3 times and compared with control observations of Artemia salina shrimp for 24 hours. The percentage of Artemia salina shrimp mortality was calculated by the following equation:

\section{$\%$ Mortality $=$ The number of dead larvae i $\times 100 \%$}

The number of larvae test

The LC- ${ }_{50}$ value was obtained using the linear regression equation formula $y=a x+b$. The value of $y$ represented the probit value at $50 \%$ of larval mortality according to the Miller Tainter probit method, while the $x$ data showed the logarithmic value of the concentration of the test solution ${ }^{13}$. The LC- $_{50}$ value was obtained from the concentration of the solution which caused the death of $50 \%$ of the larvae.

\section{RESULTS AND DISCUSSION}

\section{Phytochemical test}

Based on Table 1, matoa seed and fruit rind extract do not contain alkaloid and flavonoid compound, except for the methanol extract of the matoa fruit seed which were identified as containing flavonoid compound. The rind of the Matoa fruit contained more active compound than the seed, this can be seen from the several compound the skin had but not the seed, for example terpenoid and saponin. The test results showed that all extract did not contain terpenoid compound. The many types of chemical compounds were extracted according to the polarity level of the compounds contained by natural ingredient.

Table 1: Phytochemical test result of the Matoa fruit seed and rind extract

\begin{tabular}{|c|c|c|c|c|c|c|}
\hline \multirow{2}{*}{$\begin{array}{l}\text { Type of Phytot- } \\
\text { chemical Tes }\end{array}$} & \multicolumn{2}{|c|}{ Hexane } & \multicolumn{2}{|c|}{ EthylAcetate } & \multicolumn{2}{|c|}{ Methanol } \\
\hline & Seed & Rind & Seed & Rind & Seed & Rind \\
\hline \multicolumn{7}{|l|}{ Alkaloid: } \\
\hline - Mayer & - & - & - & - & - & - \\
\hline - Dragendorf & - & - & - & - & - & - \\
\hline - Wagner & - & - & - & - & - & - \\
\hline Flavonoid & - & - & - & - & + & ++ \\
\hline Tanin & +++ & +++ & - & +++ & ++ & +++ \\
\hline Fenol & +++ & +++ & - & +++ & + & +++ \\
\hline Saponin & - & ++++ & ++ & - & - & +++ \\
\hline Terpenoid & - & + & - & - & - & - \\
\hline
\end{tabular}

The content of tannin and phenol were very strong extracted by hexane solvent compared to ethyl acetate and methanol solvent, but these two compounds were the dominant compounds extracted. Phenol compound had the ability to stabilize free radicals. The phenol group was found in the seed and rind of the fruit and flowers of a plant ${ }^{6}$. Tannins were phenolic group compound that had hydroxyl bonds which can form compound ${ }^{7}$. Tannins can functioned as antioxidant, antibacterial and as metal chelers ${ }^{8}$.

\section{Toxicity Test with the BSLT Method}

Several type of secondary metabolite compound from phytochemical screening that were suspected of having biological activity need to be tested first on the test animals of Artemia salina larvae by applying the BSLT (Brine Shrimp Lethality Test) method. This method was used to find several types of new compound that have pharmacological effects $^{9}$. The result of the toxicity test of the seeds and rind skin of the matoa using the BSLT method and the Miller Tainter Probit calculation method can be seen in Table 2.

Based on Table 2, it showed that the higher the concentration of the test solution, the higher the \% of mortality of A.salina larvae and all test solution had bioactive compound that had high toxicity because they have LC- ${ }_{50}<1000$ ppm $^{9}$. Extract of Matoa seeds using all three solvents had LC- $_{50}$ with a range of $141.09-153.90$ ppm with the 
very toxic category. The highest toxicity was found in the rind of the matoa fruit extracted using hexane and methanol with IC- ${ }_{50}$ values of 109,34 ppm and $139.41 \mathrm{ppm}$, while the hexane extract had the lowest toxicity (172.98 ppm).

Table 2: The Toxicity of Matoa Fruit Seed and Rind using the BSLT Method

\begin{tabular}{|c|c|c|c|c|}
\hline $\begin{array}{c}\text { The fruit section } \\
\text { of Matoa }\end{array}$ & Solvent & $\begin{array}{l}\text { Concentration } \\
\text { (ppm) }\end{array}$ & $\begin{array}{c}\% \\
\text { Death*) }\end{array}$ & $\begin{array}{l}\mathrm{LC}_{50} \\
(\mathrm{ppm})\end{array}$ \\
\hline \multirow[t]{12}{*}{ Seed } & Hexane & 10 & 0 & 153,90 \\
\hline & 50 & 3,33 & & \\
\hline & 100 & 36,67 & & \\
\hline & 1000 & 100 & & \\
\hline & Ethil acetate & 10 & 0 & 141,09 \\
\hline & 50 & 10 & & \\
\hline & 100 & 40 & & \\
\hline & 1000 & 100 & & \\
\hline & Methanol & 10 & 0 & 153,65 \\
\hline & 50 & 3,33 & & \\
\hline & 100 & 36,7 & & \\
\hline & 1000 & 100 & & \\
\hline \multirow[t]{12}{*}{ Rind } & Hexane & 10 & 10 & 109,34 \\
\hline & 50 & 30 & & \\
\hline & 100 & 36,7 & & \\
\hline & 1000 & 93,3 & & \\
\hline & Ethil Acetate & 10 & 10 & 172,98 \\
\hline & 50 & 20 & & \\
\hline & 100 & 30 & & \\
\hline & 1000 & 86,7 & & \\
\hline & Methanol & 10 & 0 & 139,41 \\
\hline & 50 & 26,7 & & \\
\hline & 100 & 40 & & \\
\hline & 1000 & 100 & & \\
\hline
\end{tabular}

*) average of three replications

This was consistent with the result of phytochemical test on the rind of the matoa fruit extracted using hexane and methanol, which qualitatively contain saponin compound which were thought to contain toxic compound. A large number of the biological effect of saponins had been ascribed to their action on membrane. In fact, their specific ability to form pores in membrane had contributed to their common use in physiological research ${ }^{10}$.
It had been reported that bioactive component can be very toxic if given at high doses ${ }^{11}$, but will become drugs if given at low doses or measured doses, meaning that even though they were toxic, they can still be used as anticancer drug in combination with vitamin, to reduce the effect of the poison.

The calculation of the LD- ${ }_{50}$ value uses the "The normal population assumption" method or probit analysis. This method required the provision of doses that were assessed as logarithmic equivalent comparisons ${ }^{12}$. Based on the probit analysis, a log relationship curve was made for the test sample concentration and the probit value in Fig. 2 and Figure 3.

Based on the log correlation curve on Fig. 2 and Fig. 3, the concentration of seed extract and matoa rind extracted using hexane, ethyl acetate and methane solvent had a regression value $\left(R^{2}\right)$ of 0.9474 to 0.9908 which showed a different linear relationship pattern. The higher the regression value, the stronger the correlation between the log concentration and the probit \% mortality value of larvae. In the seed extract using 3 solvents and the extract of the matoa fruit rind using methanol solvent showed a sharp graphic pattern, namely at a concentration of $10 \mathrm{ppm}$. It could not cause death in Artemia salina shrimp larvae, but the use of 10 ppm hexane and ethyl acetate extract of the matoa fruit rind was able to kill $10 \%$ death.

The BSLT method can predict the level of plant extract toxicity and was not specific as an antitumor, however the toxicity of BSLT results had a positive correlation with cell toxicity against several type of cancer cells. Based on Fig. 2 and Fig. 3 at a concentration of 1000 ppm, all larvae of Artemia salina shrimp had died, which showed that the extract of the seed and rind of the matoa fruit in the three solvents contained active compound that were very toxic. According to Miller, a plant extract was called toxic if it had an $\mathrm{LC}_{50}$ value $<1000 \mu \mathrm{g} / \mathrm{mL}^{9}$.
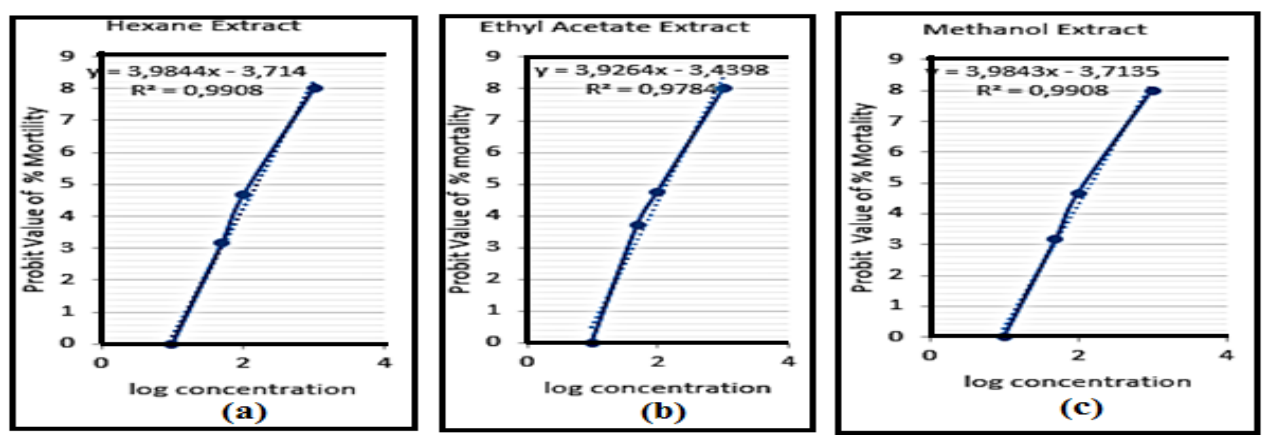

Fig. 2. Graph of the log relationship between the concentration of matoa seed extract in 3 solvents (a) Hexane (b) Ethyl Acetate (c) Methanol with the probit value of $\%$ mortality 

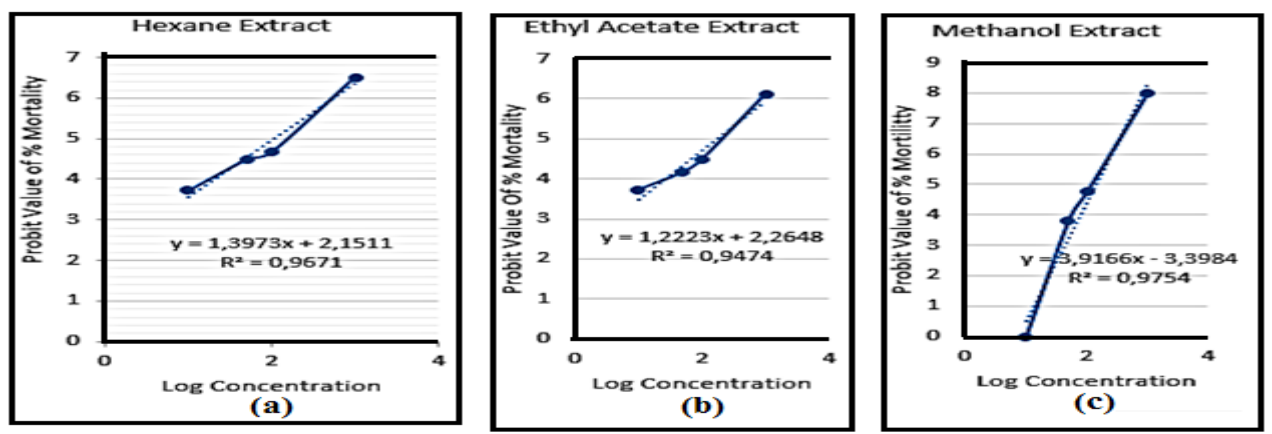

Fig. 3. The graph of the log relationship between the concentration rind of the matoa fruit extract in 3 solvents (a) Hexane (b) Ethyl Acetate (c) Methanol with the probit value of \% mortality

\section{CONCLUSION}

The toxicity value ( $\mathrm{LC}_{50}$ ) of Matoa seed extract in hexane, ethyl acetate and methanol solvents were 153, $90 \mathrm{ppm}, 141,09 \mathrm{ppm}$ and $153.65 \mathrm{ppm}$. The toxicity value (LC- ${ }_{50}$ ) of Matoa rind extract in hexane, ethyl acetate and methanol were 109, 34 ppm, 172, 98 ppm and $139.41 \mathrm{ppm}$, respectively. All the solvents had bioactive compound which had high toxicity because they have $\mathrm{LC}_{50}<1000 \mathrm{ppm}$. The highest toxicity was found in the rind of the matoa fruit extracted using hexane and methanol solvent with LC- ${ }_{50}$ values 109,34 ppm and $139.41 \mathrm{ppm}$, respectively, while the hexane extract had the lowest toxicity was 172.98 ppm.

\section{ACKNOWLEDGMENT}

The authors are grateful to Polytechnic AKA Bogor for providing the required facilities to complete out this work.

\section{Conflict of interest}

The authors disclosed no conflicts of interest related to this article.

\section{REFERENCES}

1. Hahn, Nl.; Journal of the American Dietetic Association., 1998, 98, 974-976.

2. Mataputun, S.P., Rorong, J.A., Pontoh, J.; MIPA UNSRAT Journal., 2013, 2(2), 119-123.

3. Kuspradini,Pasedan W.F, dan Kusuma I.W.; Indonesian Herbal Medicine Journal., 2016, 1(1), 26-34.

4. Irawan, C., Hanafi, Lilis S., Henny R., and Poppy SL.; Journal of Tropical Pharma Innovation., 2017, 6(8), 403-406.

5. Coolborn, A.F. and Bolatito, B.; Journal of Natural Products., 2010, 3, 27-34.

6. Yamaguchi, S., Ohnishi, J., Sogawa, M., Maru, I., Ohta, Y., and Tsukada, Y.; Nippon Shokuhin Kagaku Kogaku Kaishi., 2002, 49, 624-627.

7. Ni Putu Adriani Astiti, Sang KS, and Yan R.; Journal of Advances in Tropical Biodiversity and Environmental Sciences., 2019, 3(1),
5-7.

8. Hayes W, Dipasquale LC.; London: The Gillette Company., 2001, 853-873.

9. Meyer, B.N., Ferrigni, N.R., Putnam, J.E., Jacobsen, L.B., Nichols, D.E., McLaughlin, J.L.; Planta Medica., 1982, 45, 31-34.

10. Choi S, Jung SY, Kim CH, Kim HS, Rhim H, Kim SC \& Nah SY.; Journal of Ethnopharmacology., 2001, 74, 75-81.

11. Lestari, D, ; R. Kartika and E. Marliana; Indonesian Pharmaceutical Research Journal., 2019, 1(1), 80-90.

12. Mntor R. Hamidi, Blagica J., Tatjana KP. ; Macedonian Pharmaceutical Bulletin., 2014, 60(1), 9-18.

13. Miller C.L and M.L. Tainter. Estimation of LD 50 and its error by means of log-probot graph paper. Proc.Soc. Exp. Biol. Med., 1944, 57, 261-264. 